\title{
perifèria
}

Número 20 (2), diciembre 2015

revistes.uab.cat/periferia

\section{¿Por qué hay canciones que perduran?}

\section{La historia interminable de una canción: Txoria txori}

\author{
Josune Albisu Barandiaran - UPV_EHU ${ }^{1}$
}

DOI: http://dx.doi.org/10.5565/rev/periferia.483

\section{Resumen}

El principal objetivo de este artículo es analizar una canción, Txoria txori, para deducir cuales han sido las principales características que la han convertido en "Himno popular", permitiéndola perdurar en el tiempo. Dentro de las principales características, dos han sido verdaderamente reseñables: por una parte, la plasticidad, y por otra, la sencillez y estructura clara de la canción.

Palabras Clave: canción, Txoria txori, plasticidad, creatividad.

\begin{abstract}
The main object of this article is to analyze a song, The Bird will be a Bird, in order to discover the main characteristics which have enabled it to last through time. Amongst other factors, two stand out: on the one hand, the song's plasticity; on the other, the simplicity of the song and its clear structure.
\end{abstract}

Key words: song, The Bird will be a Bird, plasticity, creativity.

\section{La historia interminable de una canción: Txoria txori}

\footnotetext{
"Hay obras de arte que producen efecto porque quieren producirlo. Y las hay, a su vez, que lo producen por el simple hecho de existir." (Furtwängler, 2011:16)
}

\footnotetext{
${ }^{1}$ Enviar correspondencia a: josune.albisu@ehu.eus
} 


\section{perifèria}

Número 20 (2), diciembre 2015

revistes.uab.cat/periferia

En este artículo propongo analizar una conocida canción vasca, Txoria txori ("El pájaro es pájaro") del cantautor Mikel Laboa, con el objetivo de explorar las características que le han permitido perdurar intacta durante casi medio siglo, convirtiéndose en "Himno popular". Me voy a centrar en dos factores que me parecen destacables: primero, la plasticidad, característica de la música-letra del compositor y de los significados que cobra una canción para un individuo o un colectivo; segundo, la sencillez y estructura clara de la canción.

Partiendo de las reflexiones teóricas pertinentes y antes de avanzar en el desarrollo de estas consideraciones, es preciso contextualizar tanto el compositor como la canción para seguidamente indagar en el proceso de la composición, vivencia y permanencia de Txoria txori.

\section{Reflexiones teóricas}

Voy a introducir dos conceptos imprescindibles para mi análisis: la música como actante $^{2}$ y la creatividad. Parto de la afirmación de que la música es agente activo en las relaciones humanas $y$, en este sentido, forma parte de la construcción de la identidad tanto individual como colectiva, como señala Said (2001:38):"ninguna identidad cultural aparece de la nada; todas son construidas de modo colectivo sobre las bases de la experiencia, la memoria, la tradición (que también puede ser construida e inventada), y una enorme variedad de prácticas y expresiones culturales, políticas y sociales". Además de ser un medio de comunicación que ayuda a la cohesión del entramado social para crear, mantener o inventar nuevas identidades, creo necesario destacar que por medio de la música podemos expresar sentimientos y emociones que difícilmente podríamos hacer mediante palabras. El antropólogo Roger Bartra recoge esta idea de la filósofa Susanne Langer quien

\footnotetext{
2 actante: Término originalmente creado por Lucien Tesnière y usado posteriormente por la semiótica para designar al participante (persona, animal o cosa) en un programa narrativo (<www.brunolatourenespanol.org/00_Glosario_actante.htm>).
} 


\section{perifèria}

Número 20 (2), diciembre 2015

revistes.uab.cat/periferia

sostiene que: "hay un isomorfismo entre emociones y música, (...) es decir, que la música revela estados de ánimo y sentimientos que no pueden ser expresados tan bien mediante el lenguaje u otros sistemas simbólicos" (Bartra 2006:164). Pero sobre todo quiero recoger una idea de Bartra con respecto a la música que me parece excepcionalmente pertinente: "la música, además de representar estados internos de autoconciencia es ella misma un estado externo de la conciencia" (ibid., 168). Es decir, se entiende la música como una extensión de nuestro cerebro interior, convirtiéndose de este modo en un cerebro exterior o lo que él denomina "exocerebro". La música como extensión de nuestro cuerpo, una forma de estar presente de un modo intangible, pero con resultados visibles.

El siguiente concepto que, junto a la música y sus características, considero clave y de hecho constituye uno de los ejes principales de este artículo - es la creatividad. Un concepto que hace de bisagra-apertura entre lo imaginario y el mundo físico en la experiencia del ser humano. La creatividad musical hace posible que tengamos música y canciones. Pero, ¿qué se entiende por creatividad? Adopto la definición del psicólogo Czikszentmihalyi (2011), el cual formula otra pregunta para poder definir la creatividad: ¿Dónde está la creatividad? Esta es su respuesta: "la creatividad es el resultado de la interacción de un sistema compuesto por tres elementos: una cultura que contiene reglas simbólicas, una persona que aporta novedad al campo simbólico y un ámbito de expertos que reconoce y validan la innovación" (Czikszentmihalyi 2011:21).

Por lo tanto, al analizar la canción Txoria txori, la creatividad musical dependerá de la dialéctica que se establece, en primer lugar entre el creador, la canción y el campo - en este caso nos referiremos al público en general - que valora dicha canción. $Y$ digo primeramente porque a lo largo de la exposición veremos que la canción se desprende del autor y toma 'vida propia'. Esta definición de creatividad pone en interacción un círculo de tres elementos - autor, canción y personas que valoran la obra - que a la vez sirve para dinamizar otro círculo que lo constituye la música en interacción con individuos y colectivos, formando y conformando nuevos espacios y atmósferas. Desarrollaré por lo tanto, uno de los intereses de la Antropología Musical según Martí i Pérez (1992:210): "el fenómeno musical 


\section{perifèria}

Número 20 (2), diciembre 2015

\section{revistes.uab.cat/periferia}

interesa no solo como 'cultura', en el sentido más restringido de 'patrimonio', sino también como elemento dinámico que participa en la vida social del hombre, y al mismo tiempo la configura".

En referencia a las dos características: respecto a la sencillez de la melodía y letra, me basaré en afirmaciones hechas por el director de orquesta Wilhelm Furtwängler. Cuando nos preguntamos por qué hay obras (en nuestro caso canciones) que gustan más que otras o por qué hay obras que perduran más que otras, Furtwängler (2011:12) nos contesta diciendo que entre otras razones hay una que es práctica: "Estas obras se caracterizan por una gran claridad y una estructura fácil de abarcar en su conjunto, por una plasticidad creativa que ni siquiera una interpretación deficiente y confusa echaría a perder".

Teniendo en cuanto la plasticidad de la melodía, tomaré como punto de partida la descripción que hace el escultor y escritor Jorge Oteiza (1908-2003) para comprender mejor la naturaleza plástica de la misma. Según dicho autor, para comprender mejor la música, es necesario reflexionar sobre la naturaleza plástica de la misma:

\footnotetext{
"Para una verdadera comprensión de la música es necesario que distingamos su cuerpo material. Es como en toda plástica, el Espacio. Un espacio, la elección de cuya forma y mecanismo, es labor personal del compositor (...) Se ve la música con el mismo rigor y exacto sentido que una estatua. La música no se oye, se ve (...) Oír música es reconstruir el esquema geométrico en que el autor ha apoyado su obra, secretamente, o de un modo claro." (Etxebeste 2014:162)
}

Lo que podemos observar en estas reflexiones es que el espacio musical, es un espacio imaginario. Es decir que la re-creación que podamos hacer de una música en concreto (una vez entendida la arquitectura originaria), se puede adecuar a nuevos esquemas geométricos, manteniendo los cimientos de la original. Es aquí donde a mi parecer tiene lugar la plasticidad de Txoria txori: un espacio imaginario en el que capturamos la arquitectura de una canción y nos permite, nos invita diría, 


\section{perifèria}

Número 20 (2), diciembre 2015

revistes.uab.cat/periferia

incluso a re-vivirla, re-construirla a nuestra manera, o a la manera que las nuevas generaciones de músicos la han entendido, haciendo versiones o interpretándola. La plasticidad es entendida como la capacidad de adecuarse a diferentes situaciones y contextos, que tanto individual como colectivamente se puedan crear. Esta plasticidad está en estrecha relación con la ambigüedad, característica específica de la música.

En base a esta reflexión se muestran dos vertientes diferentes que ha recorrido Txoria txori: primero la adopción de la canción por las nuevas generaciones de músicos de estilos diferentes (punk, rock, sinfónica...) para hacer versiones, nuevas interpretaciones y adaptaciones varias; segundo, Txoria txori como fuente de inspiración en otras expresiones artísticas, utilizando el ejemplo de la danza contemporánea.

\section{La época y el autor}

El año 1968 (un año antes que se compusiera Txoria txori) fue marcado como el año que conmocionó al mundo. Marca un hito en la historia: fue el año en el que "Ios jóvenes tomaron la calle". Los años '60 y '70 se caracterizan por las revueltas y rebeldías que se dieron. Movimientos estudiantiles fueron la tónica general de aquella época.

Si nos acercamos a España, Kurlansky (2004) narra la situación imperante en los años 60:

El generalísimo Franco se hallaba en su vigésimo noveno "año de paz" desde que asumiera el control del país durante la guerra civil. Pese a tratarse de una dictadura represiva, había que concederle que lo era menos que la de su vecino Portugal, gobernado por el autocrático Antonio de Oliveira Salazar. En años recientes la resistencia al régimen de Franco había sido aplastada mediante purgas sangrientas en las que se eliminaba o encarcelaba a millares de españoles. Al quedar destruida la resistencia, la represión se había suavizado. Incluso habían regresado algunos refugiados de la guerra civil. Pero en 1967 una nueva generaciónde estudiantes- arrojaban piedras y exclamaban: "iLibertad!" y "iMuerte a Franco!" (Kurlansky 2004:41). 


\section{perifèria}

Número 20 (2), diciembre 2015

\section{revistes.uab.cat/periferia}

La contracultura tuvo lugar en el País Vasco en un momento en el que las condiciones sociales eran especiales. Se trata por tanto de una nueva generación posterior a una guerra (a nivel mundial la segunda guerra mundial y a nivel estatal la guerra civil española) y dentro de un régimen dictatorial, el cual destruía toda señal o signo que amenazara la unidad de España. Un ejemplo claro es la prohibición de la lengua vasca.

Fue en esta mezcla de juventud, rebeldía, dictadura y clandestinidad donde el arte, y la música en concreto, jugaron un papel importante en el País Vasco. Uno de los artistas más influyentes en el ámbito de la cultura vasca fue Jorge Oteiza, impulsor de nuevos proyectos para activar, desde un punto de vista estético y político, la reconstrucción de la identidad del "alma vasca", que tiene en cuenta varios ámbitos: educación, danza, cine, deportes, música y poesía.

Otro sería el cantautor Mikel Laboa, quien en palabras de su mujer y biógrafa, Mari Sol Bastida: "hacia la primavera de 1965, empezó a dar los primeros pasos para poner en práctica esa idea de grupo que tenía como referente a Setze Jutges y la Nova Canzço" (Bastida 2014:149).

Los primeros contactos para formar un grupo de artistas fueron con Benito Lertxundi y Lurdes Iriondo, para más tarde ir adhiriéndose más artistas al grupo, Ilamado Ez Dok Amairu (No hay trece). Dentro de este grupo, activo durante 7 años - desde 1965 al 1972 - se crearon los cimientos de grandes amistades tanto artísticas como personales. Uno de ellos fue la relación entre Mikel Laboa y Josean Artze.

La canción Txoria txori está basada en un poema escrito por Artze en una servilleta de papel del bar Aurrera de Donostia, y que Mari Sol Bastida se guardó porque le gustó. Se la enseñó a Mikel y también le gustó, por lo que pronto le puso música (Bastida 2014). Fue en el año 1969 cuando se presentó por primera vez en público. En aquellos años una de las pocas formas que tenían los jóvenes para juntarse y relacionarse eran los conciertos (aparte de poder hacerlo en misa mayor).

En aquel contexto, Mikel Laboa creó una forma de hacer, una forma de presentar en público su propuesta musical que a lo largo de los años se ha valorado 


\section{perifèria}

Número 20 (2), diciembre 2015

revistes.uab.cat/periferia

positivamente. Digo esto, porque cuando un artista toma parte en un concierto ha hecho una reflexión previa, en el sentido de que tiene que tener en cuenta no solo el lado estético, sino también el histórico y social. Atendamos las palabras de Nicolas Bourriaud, historiador y crítico de arte: "Los artistas encaran su trabajo desde un punto de vista triple, a la vez estético (¿cómo traducirlo materialmente?), histórico (¿cómo inscribirse en un juego de referencias artísticas?) y social (¿cómo encontrar una posición coherente en relación con el estado actual de producción y de las relaciones sociales?)" (Bourriaud 2013:49).

Creo que es una perspectiva a tener en cuenta porque entiendo que, partiendo de la afirmación de Bourriaud, un concierto (entendido como espacio en los que los artistas presentan sus propuestas desde este triple punto de vista) es parte de esa red social que ayuda a configurar identidades y formas de entender el entorno. Como he dicho, es una perspectiva que permite sobre todo conocer la forma de hacer del artista $y$, aunque sea condicionante, en cuanto a la tendencia que pueda marcar un artista en el ámbito social, pienso que el resultado de un concierto es la interacción entre artista, obra y público. Por tanto, es a partir de esta relación desde donde se van creando, configurando o inventando nuevas redes o estilos de relación.

A continuación, hablaré de las dos características mencionadas arriba: la sencillez y claridad en cuanto a la estructura por un lado, y la plasticidad por otro.

\section{Una canción sencilla, clara y plástica.}

Txoria txori (AEK 1995:147) 


\section{perifèria}

Número 20 (2), diciembre 2015

revistes.uab.cat/periferia

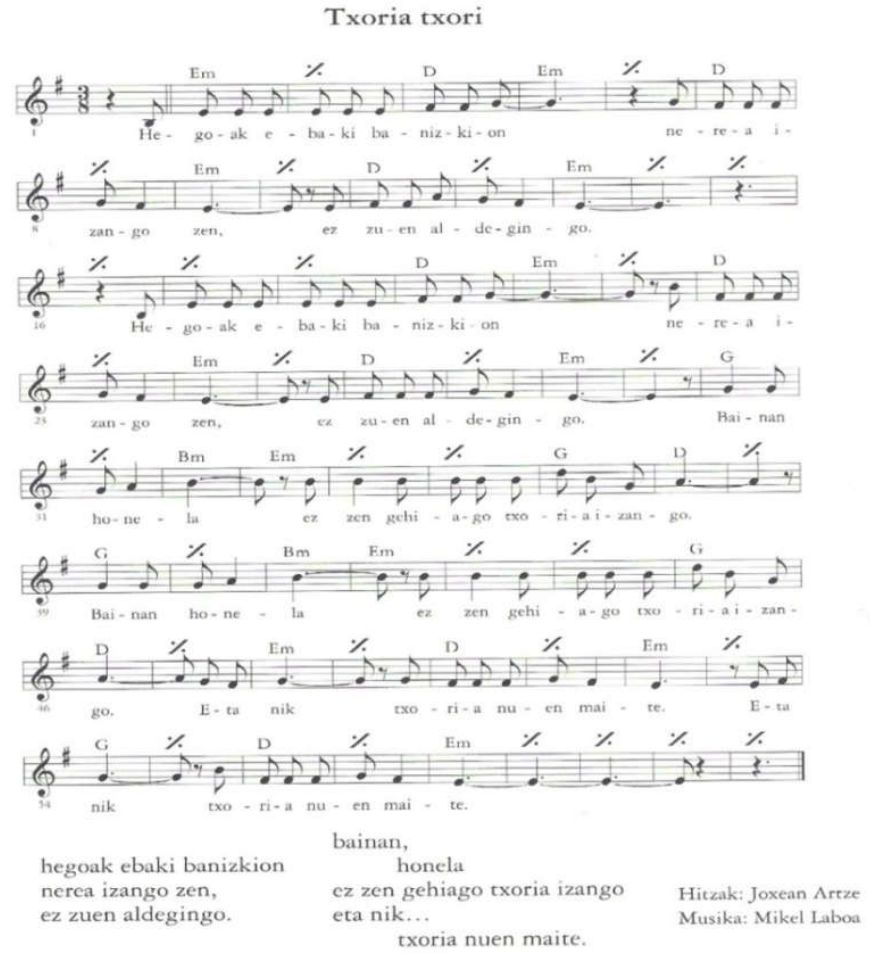

Si analizamos la partitura veremos que la melodía está escrita en Em. El compás es de $3 / 8$. La tesitura de la melodía oscila entre los intervalos de tercera y quinta, es decir, entre las notas Sol y Si (dentro de la escala de Em). Y en cuanto a la estructura corresponde a la siguiente forma: AABBCC. En otras palabras, es una melodía sencilla que empieza en anacrusa, fácil y agradable de cantar.

En cuanto a la letra ${ }^{3}$, como he dicho, fue un poema escrito por Joxean Artze. Un poema sencillo y a la vez profundo. El poema habla sobre un pájaro al que si le

\footnotetext{
${ }^{3}$ Letra de Txoria txori: Si le hubiera cortado las alas sería mio, no se habría escapado. Pero, así no sería pájaro, y yo amaba al pájaro [traducción propia].
} 


\section{perifèria}

Número 20 (2), diciembre 2015

revistes.uab.cat/periferia

hubiéramos acortado las alas, no hubiera podido volar; y concluye diciendo que entonces dejaría de ser pájaro y lo que en realidad queríamos era tener un pájaro.

La ambigüedad del significado de la letra ayuda a que la canción pueda resultar coherente en diferentes espacios y situaciones. La letra no constriñe la canción para que esta sea clasificada en un sitio y lugar concretos. Más bien diría que se da una simbiosis entre letra y música que la hace libre para que se adapte a múltiples situaciones como lo ha mostrado durante todos estos años.

La sencillez y claridad de una canción es importante a la hora de cantarla, sobre todo para la gente de a pie, porque normalmente cantamos regular (hay gente que muy bien) y una canción sencilla ayuda a soltarte a cantar y no sentirte incómoda. En este sentido Txoria txori invita a ser cantada, tanto por su sencilla melodía como por una letra fácil de aprender. La mejor manera de mostrar esta afirmación sería escuchar la canción y comentarla, pero también nos podemos hacer una idea con las palabras que Juan Gorostidi, en su libro titulado Lau kantari Beñat Achiary, Mikel Laboa, Imanol Larzabal eta Ruper Ordorika (2011) nos narra una experiencia con respecto a Txoria txori:

"Hace poco escuché en la radio a un joven viajero vasco que anduvo por África, diciendo lo bien que cantaban esta canción los niños y militares de no sé qué comarca (que los llevaría a la radio la siguiente vez y que no los diferenciaríamos de otros de nuestro entorno). "Egoooak ebaaaki banizkiooon..." cantamos todos aquí, revolucionario o ertzaina, borracho o abstemio, creyente o no creyente, viejo y joven (no me vais a creer pero es la pura verdad: he pasado este año el mismo día cuatro veces- no con mucho tiempo de distancia- en Semana Grande de Donostia por el Boulevard que estaba lleno de gente, y las cuatro veces, un cantante callejero que canta canciones vascas con gran éxito, estaba cantando Txoria txori! (Gorostidi,2011:65-66)[traducción propia]

Pensando un poco en esas personas de diferente oficio, edad y religión, podemos concluir que con canciones como Txoria txori, entramos en una comunidad, no de un grupo o colectivo concreto, ni de un momento concreto (un concierto, una fiesta), sino de una especie de supra comunidad que engloba a cualquier ser vivo 


\section{perifèria}

Número 20 (2), diciembre 2015

revistes.uab.cat/periferia

con su necesidad de conexión y comunión. Una supra comunidad que tiene en cuenta la simplicidad o si se quiere la sencillez del ser vivo, como ser efímero y eterno en esencia.

Byrne define de este modo su experiencia cuando canta en directo: "Hay algo especial en la naturaleza colectiva del público de una actuación en directo, la experiencia compartida con otra gente en un lugar, sintiendo lo mismo al mismo tiempo, que no es análogo a la música escuchada con auriculares" (Byrne, 2014: 80).

Es bastante evidente por tanto, que una canción sencilla como Txoria txori se haya convertido en himno popular, en esa canción que recurrimos cuando tenemos la necesidad de relacionarnos, de expresar eso que con palabras no se puede, como dice Bernstein: "The greatest gift he could give man was the ability to talk and communicate. And a big part of communication is music" (Bernstein, In Cott, 2013: 73).

Cuando se habla en general de música o de canciones, no se está analizando su calidad, si está hecha de buen material, si tiene dos guitarras eléctricas o tres baterías, esto lo dejamos para los entendidos. Cuando la gente de a pie habla de canciones o canta canciones está hablando de sí misma, está hablando de su pasado, de su memoria, por medio de la cual ha creado su identidad. Por tanto, una canción puede activar la memoria y traer al presente un pasado lejano, y hacer que lo revivamos. Una canción puede llegar a ser símbolo de identidad colectiva, Fischer nos recuerda que: "en cada obra de arte verdadera se suspende la división de la realidad humana en lo individual y lo colectivo, en lo específico y lo universal; pero pervive como factor suspendido en una unidad recreada" (Fischer,2001:71). En consecuencia podemos entender la canción como una prolongación de nuestro ser que conecta con otros seres en otro nivel (no visual pero si sensitivo); podríamos llamarlo universal. Hay pocas canciones que transcienden el tiempo y logran ese nivel universal: Txoria txori es una de ellas. 


\section{perifèria}

Número 20 (2), diciembre 2015

revistes.uab.cat/periferia

¿Dónde reside el misterio de cómo se crea la música y nos relacionamos con ella y mediante ella? El director de orquesta Michel Tilson-Thomas así lo expresa ${ }^{4}$ :

"Como toda la música, en esencia no es acerca de nada. Es tan solo un diseño de tonos, silencios y tiempos (...) y los tonos, las notas, como saben, son solo vibraciones (...) La manera en la que reaccionamos a las diferentes combinaciones de este fenómeno es compleja y emocional, y no se comprende del todo"

Es decir que, según el diseño que requiere la combinación de tonos, silencios y tiempos, podemos construir una canción (la letra también cuenta), que nos influya tanto a nivel personal como colectivo.

$Y$ es este espacio-visual imaginario donde tienen cabida toda clase de manifestaciones colectivas y representaciones simbólicas que ha sido capaz de absorber la naturaleza plástica de una canción concreta, en nuestro caso Txoria txori. Por lo tanto, centrándonos en la música de Txoria txori vemos que la combinación de los tonos, notas y tiempos han sido colocados en una posición que ha dado lugar a una composición válida para estados emocionales muy diferentes. Txoria txori se canta tanto en una boda como en un funeral; se han hecho versiones empezando por una versión punk y acabando con una versión sinfónica. Y no podemos dejar de lado su capacidad de inspirar en otras disciplinas artísticas.

Con motivo del premio Adarra que se concedió a Mikel Laboa el 22 de Junio del 2014, Iñaki Zarata escribió un artículo titulado Canciones con alma de goma. En el mismo comenta: "El encuentro entero evidenció una vez más la particular flexibilidad del cancionero de Laboa para adaptarse a todo tipo de formatos" (Zarata, en Diario Vasco 22-06-2014). Y sigue: "Nos hizo recordar el conocido humor del propio Mikel cuando en algún inesperado encuentro popular con su "Txoria txori" se le sugería el carácter 'rubber soul' ('alma de goma', título de un disco de los Beatles) de su obra. Aceptaba la comparanza, pero siempre que esa forma gomosa no se refiriera a su anatomía física, incapaz de competir, decía, con las flexibles cinturas de los rockeros" (idem).

\footnotetext{
${ }^{4}$ Ver: http://www.ted.com/talks/view/lang/es//id/1440
} 


\section{perifèria}

Número 20 (2), diciembre 2015

revistes.uab.cat/periferia

Quisiera argumentar que a la plasticidad de la música hay que añadirle la plasticidad creadora del compositor. Además, hay que añadir un tercer elemento para que esta plasticidad transcienda al tiempo: cuando la canción toma vida propia, cuando un individuo o colectivo la hace suya y la adecua a sus necesidades y deseos. Creo que es un claro ejemplo de plasticidad que mostraré con la ayuda de John Cage:

"Vemos que para mirar un objeto, una obra de arte, por ejemplo, tenemos que verla como algo que está sucediendo, no como la hizo quien la creo, sino como se hace mientras la vemos." (Cage 2012[1961]:223)

Esta afirmación encaja perfectamente con mi argumentación en cuanto a la plasticidad de una canción, en este caso, Txoria txori. Tenemos ante nosotros la partitura con letra incluida. Cada vez que cogemos la partitura, es como si fuera la primera vez. Estamos reconstruyendo la canción.

Una canción conectada con un sentimiento adquiere una nueva dimensión y si usamos la creatividad podemos desarrollar a partir de esa canción, gracias al espacio imaginario en la que está construida, nuevas ideas, nuevos enfoques que atraen a la vez otras ideas y relaciones con distintas disciplinas, extendiéndose como un rizoma en las culturas y en consecuencia aportando nuevos conocimientos.

\section{Txoria txori como fuente de inspiración}

Una tarde de otoño del año 2011 encendí la radio y estaba hablando Itziar Mendizabal, solista del Royal Ballet de Londres. La razón de dicha entrevista era la 7a Gala 'Los vascos y la danza', organizada por la Asociación Bilbao Ballet y que todos los años invita a artistas vascos que están desarrollando su carrera en el extranjero. En la gala Mendizabal iba a interpretar dos coreografías creadas por Jon Ugarriza y una de ellas estaba basada en la canción Txoria txori. La elección de esta canción para la coreografía no fue casualidad. En el preciso momento que encendí la radio, la bailarina estaba explicando lo que significaba para ella la 


\section{perifèria}

Número 20 (2), diciembre 2015

revistes.uab.cat/periferia

canción Txoria txori. Relató que cuando tenía 14 años decidió irse a Madrid para empezar su carrera como bailarina y su padre le envió una carta, en la que le escribió la letra de la canción en cuestión. Desde entonces es una canción especial para ella.

El 28 de octubre de 2011 fuimos al Euskalduna (Bilbao) para ver la 7a Gala 'Los vascos y la danza'. Cuando llegó el momento de interpretar la canción Txoria txori, en la pantalla del escenario pusieron la foto de Mikel Laboa que abarcaba el total de la pantalla. Salieron al escenario Itziar Mendizabal y Johannes Stephan. La canción tomó vida por medio de Mendizabal, quien se convirtió en el pájaro que ansía la libertad, que tiene como salvación el amor hacia los demás. Cuando terminaron el baile, Mendizabal y Stephan hicieron un gesto de saludo mirando hacia la foto de Laboa, un homenaje-agradecimiento-reconocimiento, por haber compuesto dicha canción. El público respondió con una gran ovación. Las personas presentes sentimos un momento de magia que pone en circulación ciertos valores colectivos y positivos (en este caso, como la libertad o el amor), con los cuales se pierde la conciencia de uno mismo para sentir esa unidad que se adquiere en momentos de especial emoción.

\section{Txoria txori desde el punto de vista de músicos y nuevas generaciones}

Si entramos en internet y ponemos las palabras Txoria-txori aparecen infinidad de versiones de la canción. Tanto versiones hechas por artistas y grupos reconocidos ${ }^{5}$, como versiones hechas por personas aficionadas a la música. Siguiendo con esta variedad que representa la riqueza de una simple canción, me gustaría comentar la buena acogida que tiene Txoria txori en cuanto a las nuevas generaciones se refiere. Por dar un dato cuantitativo, en el año 2012, en el Estado francés se vendieron 60.000 copias del CD "Les Voix Basques", que incluye Hegoak - la canción Txoria txori pero con otro título-, cantada por Anne Etchegoyen. En este

\footnotetext{
5 Ver: Berasarte, María <http://www.youtube.com/watch?v=Z0d3ooXwh94>; Irazoki, Joseba <http://www.youtube.com/watch?v=64XpoipZ5QU>; Orfeon Donostiarra, Mikel Laboa < http://www.youtube.com/watch?v=nCwkq8H5YHk->
} 


\section{perifèria}

Número 20 (2), diciembre 2015

\section{revistes.uab.cat/periferia}

caso, Txoria txori es una canción atemporal cantada por una joven que representa el presente con un prometedor futuro. De alguna manera, la canción que es tradición, revive en una nueva y joven voz. Mediante esta nueva y joven voz se reafirma por medio de la canción, reconociendo y reforzando, el imaginario colectivo de pertenencia a una comunidad. Pero también esta nueva y joven voz nos trae una nueva estética, una forma diferente de escuchar la canción ${ }^{6}$. Lo importante de todo esto es esa canción que hace posible el encuentro entre pasado, presente y futuro; esa canción, vista desde un punto creativo, que hace posible la relación arte-mundo-personas. Es por ello que, una vez más nos asombramos ante el poder de la música y el lenguaje, no solo por la capacidad de activar nuestras emociones, sino por la posibilidad de transcender. En general, como nos recuerda Duchamp, el acto creativo no es ejecutado únicamente por el artista, también hay que tener en cuenta que el espectador lleva la obra al contacto con el mundo externo, al descifrar e interpretar sus cualidades internas, de esta manera contribuyendo al acto creativo. Esto se vuelve más obvio, según Duchamp, cuando la posteridad nos da su veredicto final y algunas veces rehabilita a artistas olvidados (Duchamp 1957).

Resulta que como hemos resaltado en este artículo, Txoria txori de alguna manera nos envuelve y hace sentirnos como si fuéramos una sola persona, pero no sabemos cómo lo consigue. Además de los factores que hemos mencionado: la importancia del intérprete y la época; la importancia de cantarla en directo, los conciertos; la sencillez y plasticidad de la canción, me gustaría añadir una hipótesis o posible respuesta a esta pregunta (¿cómo logra esa sensación de unidad?), que puede estar relacionada con la idea que he presentado en la introducción del artículo: La música como extensión de nuestro cuerpo.

Voy a contar una experiencia simple pero significativa para mí, para argumentar dicha hipótesis. Estando en clase de canto, el profesor sugirió un ejercicio en base a

\footnotetext{
${ }^{6}$ Ver: Etchegoyen, Anne < http://www.youtube.com/watch?v=HvJxSnYWdp0>
} 


\section{perifèria}

Número 20 (2), diciembre 2015

revistes.uab.cat/periferia

una melodía. Empezó él a cantar y yo iba por detrás de su melodía intentando que fueran a la par, cuando de repente el profesor se calló, yo me caí, o dicho de otra manera el sonido que salía de mi boca se derrumbó.

Es decir, que mi sonido (por denominarlo de alguna manera) se estaba sosteniendo en el suyo, era como si un sonido arrastrara al otro para estar a la misma altura. Estaban juntos. Esta simple anécdota me ha hecho reflexionar en el sentido de que el sonido es, como nos dice Tilson-Thomas, vibración, es físico intangible digamos. Aquí es donde enlazo con la idea de Bartra en cuanto a que la música es como una extensión de nuestro cerebro interior. Cuando cantamos juntos, esas vibraciones que provienen de los cerebros internos, se juntan, se abrazan, cosa que es imposible que hagamos físicamente cuando estamos cantando (solo podemos abrazar a los de al lado). Lo que hacemos es, abrazarnos mediante los sonidos, porque ellos sí que pueden hacerlo. Ese abrazo que sentimos, esa unión, no es figurativa o simbólica es física-intangible.

\section{Conclusión}

Escribir sobre una canción sin poder incluir la música, da la sensación de estar haciendo un trabajo incompleto, debido a que un factor a tener en cuenta es justo "la escucha" de dicha canción. Seguramente, en breve, gracias a las nuevas tecnologías tendremos acceso, tanto a textos como a sonidos a medida que vamos leyendo. Pero por ahora nos conformaremos con tener acceso directo en internet para poder completar este artículo con la necesaria escucha de Txoria txori.

La materia con la que se construye la música, básicamente trata de vibraciones, las cuales se organizan en el espacio imaginario y con la ayuda de la creatividad se transforman en una unidad denominada canción, por supuesto, completando esta parte musical con un poema.

Este espacio imaginario al que Oteiza denomina 'naturaleza plástica de la música', es el campo en el que opera la creatividad como bisagra-apertura, creando la estructura de la canción y transmutándola al campo físico, para que a la vez sea recreada en el imaginario colectivo, donde esa canción tomará vida propia o morirá. 


\section{perifèria}

Número 20 (2), diciembre 2015

revistes.uab.cat/periferia

Como dice Becker: "Los trabajos se recrean cada vez que alguien los experimenta, se mueren cuando nadie los vuelve a experimentar" (Becker 2008:254).

Hay factores que indican la posibilidad del trascender de una canción, tales como los que se han mencionado a lo largo del artículo resaltando la sencillez con una estructura fácil y la plasticidad. Pero hay uno que escapa a todo razonamiento, a saber, el factor diferencial: tener vida propia.

Este factor no se encuentra en la estructura de la canción (música+ letra) o en el autor que la compuso, o en la gente que la canta, ni tan siquiera en la época que ha sido creada, sino en la red misma que han generado todos estos elementos. $Y$ que a lo largo de los años ha ido reafirmándose ocupando ese lugar preferente que toda obra de arte aspira: el transcender.

\section{Bibliografía}

AEK (1995). Mikel Laboa. Donostia:Elkar.

Bartra, Roger (2007). Antropología del cerebro. México: Fondo de Cultura Económica.

Bastida, Mari Sol (2014). Memoriak Mikel Laboaren biografia bat. Donostia:Elkar. Becker, Howard S. (2008 [1 $1^{a}$ ed. 1982]). Los mundos del arte. Sociología del trabajo artístico. Buenos Aires:Universidad Nacional de Quilmes.

Bourriaud, Nicolas (2013 [2002]). Estética relacional. Buenos Aires:Adriana Hidalgo.

Byrne, David (2014). Cómo funciona la música. Barcelona. Penguin Random House. Cage, John (2012 [1a ed. 1961]). Silencio. Madrid: Árdora.

Csikszentmihalyi, Mihalyi (2011 [1a ed.1996]). Creatividad. El fluir y la psicología del descubrimiento y la invención. Barcelona: Paidós.

Cott, Jonathan (2013) Dinner with Lenny. New York: Oxford University Press.

Duchamp, Marcel (1957). Conferencia de la Federación Americana de las Artes. Art. News. Vol.:56. N04. [En línea] 


\section{perifèria}

Número 20 (2), diciembre 2015

revistes.uab.cat/periferia

http://courses.ischool.utexas.edu/Smith_Kim/2007/Fall/INF385H/Duchamp_Creativ eAct.pdf (Accedido el 19 de noviembre de 2015)

Etxebeste, Elixabete (2014). Oteiza y la música. Alzuza: Fundación Museo Jorge Oteiza Fundazio Museoa.

Furtwängler, Wilhelm (2011[1 $1^{\mathrm{a}}$ ed. 1983]). Conversaciones sobre música. Barcelona: Acantilado.

Fisher, Ernst (2001[1967]). La necesidad del arte. Barcelona:Península.

Gorostidi, Juan (2011). Lau kantari: Beñat Axiari, Mikel Laboa, Imanol Larzabal,Ruper Ordorika. Iruñea: Pamiela.

Hersch, Jeann (2013). Tiempo y música. Barcelona:Acantilado.

Kurlansky, Mark (2004). 1968: El año que conmocionó al mundo. Barcelona: Destino.

Martí i Pérez, Josep (1992). Hacia una Antropología de la Música. Anuario musical: Revista de musicología del CSIC, No 47, 1992, pp. 195-226.

Oronoz, Belén (2000). Gazteri berria, Kantagintza berria. Donostia: Erein.

Said, Edward W. (2001) "Cultura, identidad e historia". En Schröder,Gerhart \& Breuninger, Helga comps. Teoría de la cultura. Buenos Aires: FCE. pp:37-53.

Zarata, Iñaki (2014). "Canciones con alma de goma". Diario Vasco, 22-06-2014 